\title{
Berberine targets epidermal growth factor receptor signaling to suppress prostate cancer proliferation in vitro
}

\author{
ZHENG-HUA HUANG, HONG-FANG ZHENG, WEI-LU WANG, YONG WANG, \\ LONG-FEI ZHONG, JIU-LONG WU and QIAO-XING LI \\ Department of Urological Surgery, Kunshan First People's Hospital Affiliated to Jiangsu University, \\ Kunshan, Jiangsu 215300, P.R. China
}

Received November 19, 2013; Accepted May 23, 2014

DOI: $10.3892 / \mathrm{mmr} .2014 .2929$

\begin{abstract}
Berberine is a well-known component of the Chinese herbal medicine Huanglian (Coptis chinensis), and is capable of inhibiting the proliferation of multiple cancer cell lines. However, information available regarding the effect of berberine on prostate cancer cell growth is limited. In the present study, LnCaP and PC-3 human prostate cancer cell lines were selected as in vitro models in order to assess the efficacy of berberine as an anticancer agent. A cell proliferation assay demonstrated that berberine inhibited cell growth in a dose-and time-dependent manner. Further investigation revealed berberine significantly accumulated inside cells that were in the G1 phase of the cell cycle and enhanced apoptosis. Western blot analysis demonstrated that berberine inhibited the expression of prostate-specific antigen and the activation of epidermal growth factor receptor (EGFR), and it attenuated EGFR activation following EGF treatment in vitro. In conclusion, the results indicate that berberine inhibits the proliferation of prostate cancer cells through apoptosis and/or cell cycle arrest by inactivation of the EGFR signaling pathway.
\end{abstract}

\section{Introduction}

Prostate cancer has become a significant worldwide public health problem. The disease is the second leading cause of cancer-related morbidity and mortality in males (1). The majority of cases of prostate cancer present as localized disease and may be cured by surgery and radiation $(1,2)$. Until recently, there were only three FDA-approved agents (estramustine, mitoxantrone and docetaxel) for chemotherapy in prostate cancer (3-5). However, numerous patients present with locally advanced or metastatic prostate cancer, which is currently

Correspondence to: Mr. Qiao-Xing Li, Department of Urological Surgery, Kunshan First People's Hospital Affiliated to Jiangsu University, 91 Quanjing Road, Kunshan, Jiangsu 215300, P.R. China E-mail: fsyx7skk@163.com

Key words: berberine, prostate cancer, epidermal growth factor receptor incurable. The modulation of intracellular signaling pathways used as a means of intervening with multistage cancer could become a molecular basis for chemoprevention (5).

Berberine is a component of the Chinese herbal medicine Huanglian (Coptis chinensis) and has been used for centuries to treat diarrhea, most likely by inhibiting mucosal chloride secretion (6). Modern pharmacological research has identified that berberine is a multi-pharmacological molecule exhibiting anti-inflammatory, anti-arrhythmic and antitumor activities (7). In a number of studies, berberine has been previously used clinically for the treatment of dysentery, hypertension and inflammation $(8,9)$. The most noteworthy function of berberine is its ability to inhibit cell growth and induce apoptosis in a number of human cancer cells (10-13). Several mechanisms have been reported to underlie the antitumor activity of berberine, including the induction of cell cycle arrest and stimulation of cancer cell caspase-dependent apoptosis (14-16). However, there is limited information concerning the effect of berberine on prostate cancer cell growth.

In the present study, the detailed underlying mechanisms of the effect of berberine on inhibiting prostate cancer cell growth in vitro were investigated. The observations of the present study provide novel insights into the action of berberine, which may aid in the identification of novel therapeutic targets and development of strategies for treating human prostate cancer.

\section{Materials and methods}

Cell culture. The LnCaP and PC-3 human prostate cancer cell lines were obtained from the American Type Culture Collection (Manassas, VA, USA). The cells were maintained in RPMI-1640 medium supplemented with $10 \%$ fetal calf serum, L-glutamine $(5 \mathrm{mmol} / \mathrm{l})$, non-essential amino acids $(5 \mathrm{mmol} / \mathrm{l})$, penicillin $(100 \mathrm{U} / \mathrm{ml})$ and streptomycin $(100 \mathrm{U} / \mathrm{ml})$ (Invitrogen Life Technologies, Carlsbad, CA, USA) at $37^{\circ} \mathrm{C}$ in a humidified $5 \% \mathrm{CO}_{2}$ atmosphere. Berberine was purchased from Sigma-Aldrich (St. Louis, MO, USA). epidermal growth factor (EGF) was obtained from Cell Signaling Technology Inc., (Beverly, MA, USA).

Cell viability assay. Cell proliferation was determined using an MTT viability assay, the most commonly used assay for determining cell growth and death. The MTT survival assay 
has been described in detail in a previous study (17). Briefly, exponentially growing cells were recultured $(5,000$ cells/well $)$ overnight in 96-well tissue culture plates. Up to $20 \mu \mathrm{l}$ of MTT (Sigma-Aldrich) was directly added to the media in each well, with a final concentration of $2 \mathrm{mg} / \mathrm{ml}$. Following a $4 \mathrm{~h}$ incubation, the medium containing MTT was discarded and $120 \mu 1$ dimethylsulfoxide was added for $10 \mathrm{~min}$. The absorbance was measured using an enzyme-linked immunosorbent assay reader (Bio-tek, Inc., Winooskie, VT, USA) at $570 \mathrm{~nm}$, with the absorbance at $630 \mathrm{~nm}$ as the background correction. The cell viability was expressed as the percentage of untreated controls. All the experiments were performed at least three times.

Cell cycle assays. The cells were removed from the culture dishes with trypsin and collected into centrifuge tubes together with the culture medium. All the contents were centrifuged for $5 \mathrm{~min}$ at $1,800 \mathrm{xg}$. The supernatant was decanted, washed once with 1X phosphate-buffered saline (PBS) and centrifuged for another $5 \mathrm{~min}$. The cells were finally fixed with $5 \mathrm{ml}$ of pre-cooled $70 \%$ ethanol for at least $4 \mathrm{~h}$. The fixed cells were centrifuged and washed with 1X PBS. Following centrifugation, the cell pellets were resuspended in $500 \mu \mathrm{l}$ propidium iodine $(10 \mu \mathrm{g} / \mathrm{ml})$ containing $300 \mu \mathrm{g} / \mathrm{ml}$ RNase (Sigma-Aldrich). The cells were then incubated on ice for $30 \mathrm{~min}$ and then filtered with a 53- $\mu \mathrm{m}$ nylon mesh. The cell cycle distribution was calculated from 10,000 cells using ModFit LT software (Becton-Dickinson, San Jose, CA, USA) using FACS Calibur (Becton-Dickinson).

Apoptosis assay. Apoptosis analysis was undertaken by a flow cytometer (Beckman, Irvine, CA, USA) and an Annexin V-fluorescein isothiocyanate (FITC)/propidium iodide (PI) kit (BD Biosciences, Sparks, MD, USA) was used to measure the percentage of apoptosis induced by berberine. The cells were removed with trypsin and collected into centrifuge tubes together with the culture medium. A total of $5 \mu 1$ Annexin V-FITC solution and $10 \mu \mathrm{l} \mathrm{PI}(1 \mu \mathrm{g} / \mathrm{ml})$ were added to the cells for $30 \mathrm{~min}$ away from the light. Flow cytometry and Annexin V-FITC apoptosis analysis were performed as previously described (18). The apoptotic rates were calculated from 10,000 cells using ModFit LT software with FACS Calibur.

Western blot analysis. The cell lysates were prepared, and western blot analysis was performed as previously described (19). Equal aliquots of the total cell protein (50 $\mu \mathrm{g}$ per lane) were electrophoresed on sodium dodecyl sulfate-polyacrylamide gels, transferred onto polyvinylidene fluoride membranes (Millipore, Billerica, MA, USA) and then blotted using primary antibodies against $\beta$-actin (C-4), phospho (p)-EGFR (Tyr 1092 m), EGFR (C-20) and prostate-specific antigen (PSA; C-19) (all from Santa Cruz Biotech, Santa Cruz, CA, USA; 1:1,000 dilution) followed by incubation with secondary horseradish peroxidase-labeled goat anti-mouse (GAM-007) and goat anti-rabbit (SC-2004) $\mathrm{IgG}$ antibodies. The protein bands were visualized using an enhanced chemiluminescence system (Union Bioscience Corporation, Hangzhou, China) with prestained markers as molecular size standards. At least three independent experiments were performed for each cell type observed.
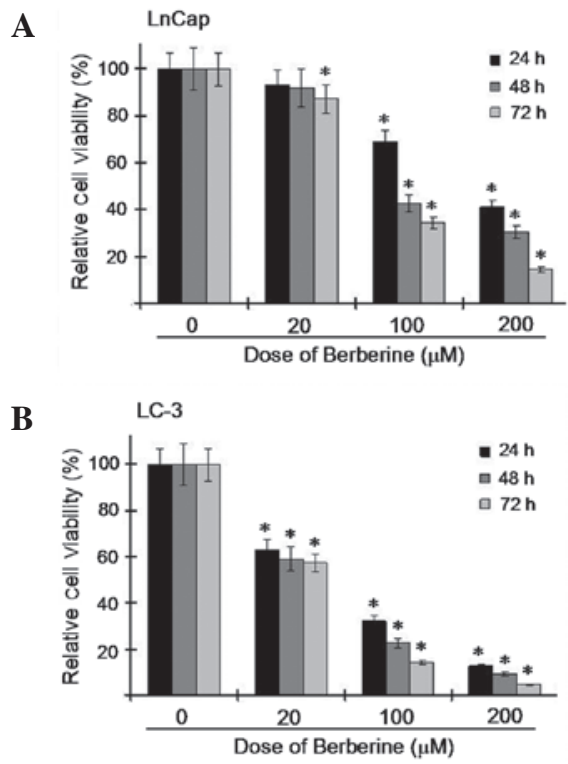

Figure 1. Berberine inhibited the proliferation of prostate cancer cells in a dose- and time-dependent manner. (A) LnCaP and (B) LC-3 cells were treated with either $0.1 \%$ dimethyl sulfoxide (as a control) or berberine (20-200 $\mu \mathrm{M})$ for $24-72 \mathrm{~h}$, and the proportion of the surviving cells was measured by an MTT assay. The bars indicate the mean \pm standard deviation from three independent experiments. ${ }^{*} \mathrm{P}<0.05$, compared with control.

Statistical analysis. Data are presented as the mean \pm standard deviation. The experimental results of the treated and control groups were compared using two-tailed Student's t-test. All the statistical tests were performed using SPSS version 17.0 (SPSS Inc., Chicago, IL, USA). P $\leq 0.05$ was considered to indicate a statistically significant difference.

\section{Results}

Berberine inhibits proliferation in prostate cancer cells. The antiproliferative effects of berberine on $\mathrm{LnCaP}$ and PC-3 human prostate carcinoma cells were investigated. The cells were treated with 20, 100 and $200 \mu \mathrm{M}$ berberine for 24,48 and $72 \mathrm{~h}$. Berberine treatment in $\mathrm{LnCaP}$ cells resulted in a significant reduction in cell proliferation at $20 \mu \mathrm{M}(\mathrm{P}<0.05)$ and $100 \mu \mathrm{M}$ $(\mathrm{P}<0.05)$ after 72 and $24 \mathrm{~h}$ treatment, respectively (Fig. 1A). Similar effects were observed in PC-3 cells (Fig. 1B). However, PC- 3 cells responded more rapidly compared with the $\mathrm{LnCaP}$ cells, with a reduction in viability observed at $20 \mu \mathrm{M}(\mathrm{P}<0.05)$ after $24 \mathrm{~h}$ treatment. These data indicate that berberine has a cytotoxic effect on prostate carcinoma cells, in p53 wild-type (LnCaP) and p53-mutated (PC-3) cells.

Berberine induces cell cycle arrest and apoptosis in prostate cancer cells. Based on this preliminary data in which a growth inhibitory effect of berberine was observed in $\mathrm{LnCaP}$ and PC-3 cells, a time point of $48 \mathrm{~h}$ after treatment was selected in order to determine the possible inhibitory effect of berberine on cell cycle progression and apoptosis. The LnCap cells demonstrated that an increased number of cells had undergone G1 cell cycle arrest at $100 \mu \mathrm{M}(\mathrm{P}<0.005) 48 \mathrm{~h}$ following treatment, compared with DMSO treatment. Simultaneously, the reduction of the G2/M phase was observed in a dose-dependent manner, indicating that berberine induces G1 phase cell cycle arrest in LnCap 

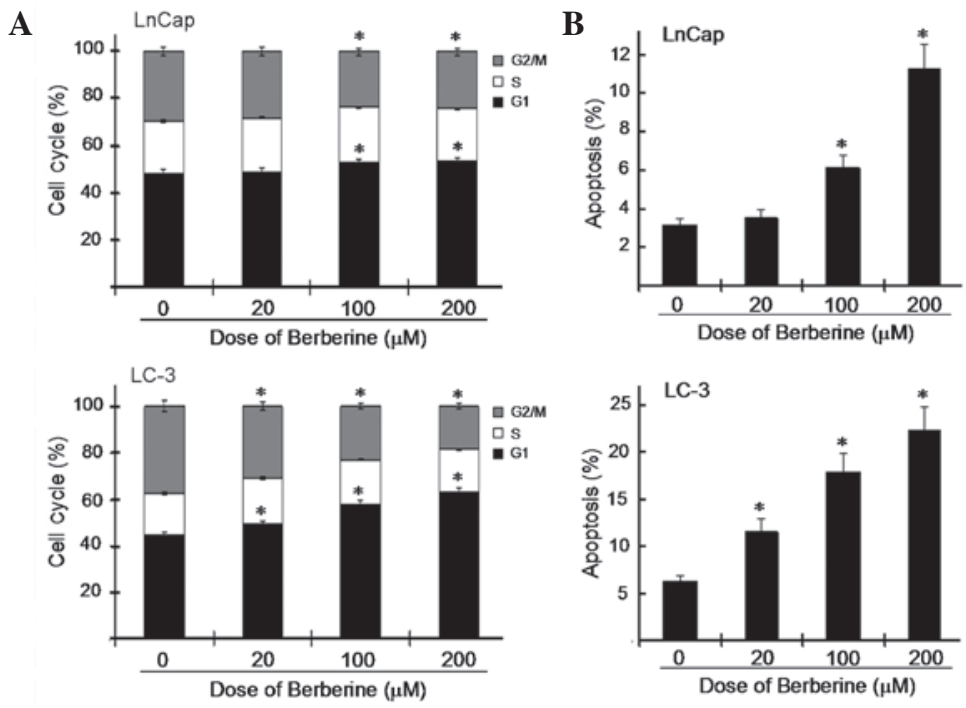

Figure 2. Berberine treatment resulted in an accumulation of cells at the S-phase and apoptosis in prostate cancer cells. (A) PC-3 cells were treated with berberine for $48 \mathrm{~h}$, and stained with propidium iodide. The population of $\mathrm{LnCaP}$ and PC-3 cells at different cell cycle phases is shown. (B) Apoptosis was determined by Annexin V staining and flow cytometry. The bars indicate the mean \pm standard deviation from three independent experiments. ${ }^{*} \mathrm{P}<0.05$, comapred with control.

A
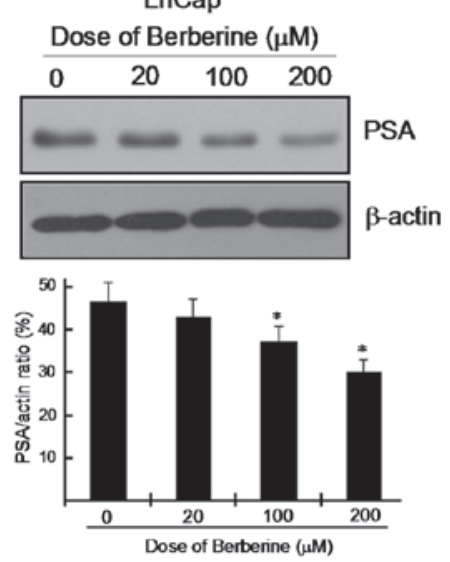

B LC-3

Dose of Berberine $(\mu \mathrm{M})$
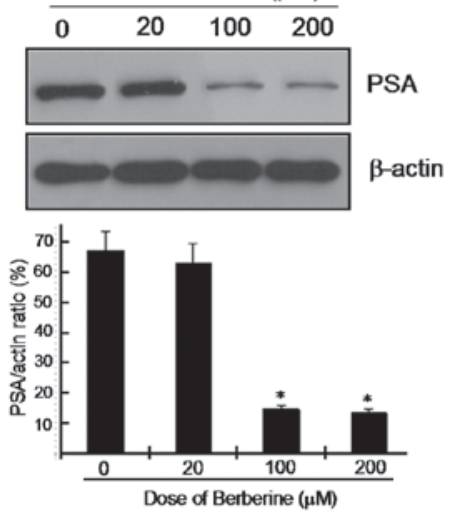

Figure 3. Berberine reduced the expression level of PSA prostate cancer cell lines. The expression levels of PSA in (A) LnCaP and (B) PC-3 cells were determined by western blotting. $\beta$-actin served as a loading control. Values indicated are the mean \pm standard deviation from three independent experiments. $\mathrm{P}<0.05$, compared with control (dimethylsulfoxide-treated cells). PSA, prostate-specific antigen.
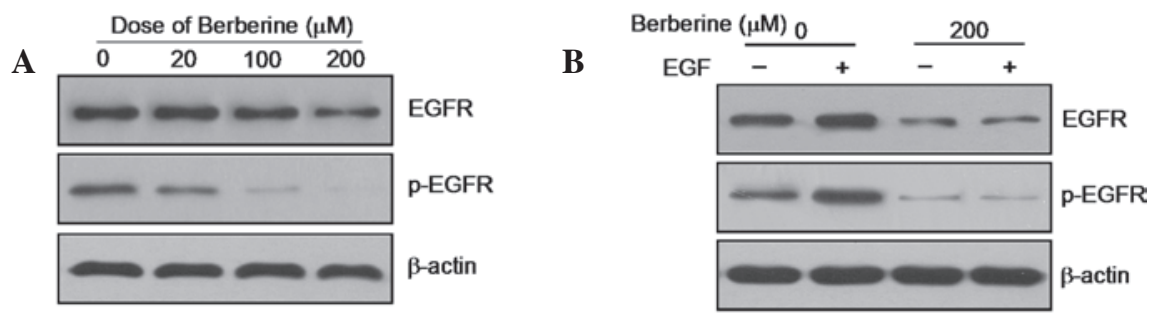

Figure 4. Berberine inhibited the expression of EGFR and the activion of EGFR stimulated by EGF. (A) Cells were cultured $48 \mathrm{~h}$ with or without berberine. (B) Cells were treated with berberine at $200 \mu \mathrm{M}$ under non-permissive conditions for $48 \mathrm{~h}$ in the presence or absence of EGF ( $3 \mu \mathrm{M})$ treatment for $5 \mathrm{~min}$. Cellular lysates were collected for western blot analysis to detect indicated signaling pathways. $\beta$-actin was used as a protein loading control. p-EGFR, phospho-epidermal growth factor receptor; EGF, epidermal growth factor.

cells. Similar results were obtained in PC-3 cells (Fig. 2A). An Annexin $\mathrm{V}$ assay was used to determine the effect of berberine on apoptosis in prostate cancer cells. Treatment of LnCap cells with berberine resulted in a significant increase in the number of apoptotic cells at a concentration of $100 \mu \mathrm{M}(\mathrm{P}<0.05)$, compared with the control cells (Fig. 2B). A similar effect was observed in the PC- 3 cells.

Berberine inhibits the expression of PSA in prostate cancer cells. PSA is a well-characterized target gene of the androgen 
receptor (20). In the present study, the effect of berberine on PSA expression in prostate cancer cells was determined. Using western blot analysis, it was identified that a low dose of berberine $(20 \mu \mathrm{M})$ resulted in marginal decrease in PSA protein levels and the inhibition of PSA at a dose of $100 \mu \mathrm{M}$ or higher in LnCaP cells (Fig. 3A). Berberine also decreased PSA expression in PC-3 cells (Fig. 3B).

Berberine inhibits the activation of EGFR and reduces the expression and activation of EGFR induced by EGF.PC-3 cells were selected to determine the effects of berberine on the regulation of EGFR expression and activity. Addition of berberine resulted in a decrease in the total EGFR and phosphorylated EGFR levels (Fig. 4A). Furthermore, EGF-stimulated EGFR activation was also inhibited by berberine (Fig. 4B).

\section{Discussion}

Prostate cancer is one of the leading causes of cancer-related mortality in males (2). Since the information regarding the effect of berberine on prostate cancer development is limited, the purpose of this study was to investigate the mechanisms of action of berberine in prostate cancer cells. The results revealed that berberine treatment of these cell lines decreased growth rates in a dose- and time-dependent manner. In general, three phases of the cell cycle control cell proliferation, which is most commonly inhibited by cell cycle arrest $(6,21-23)$. The present study demonstrated the potent inhibitory activity of berberine on cell proliferation occurs by inducing G1 cell cycle arrest in prostate cancer cells. Apoptosis is now recognized as a critical process for the normal development of multicellular organisms and is important in homeostasis. One aim of therapies for various types of cancer, including prostate cancer, is to increase the percentage of tumor cells undergoing apoptosis $(12,15,24,25)$. An Annexin V assay demonstrated that treatment of prostate cancer cells with berberine resulted in a significant increase in the number of apoptotic cells.

Several aspects of cell homeostasis, including proliferation and cell survival, are regulated by EGFR. EGFR expression or activation is implicated in multiple cancers $(16,26)$. A significant finding from the present study is that berberine significantly downregulated the expression and activity of EGFR in PC-3 cells. In addition, berberine was able to downregulate EGFR activation stimulated by EGF. Results from the present study provided novel findings regarding the antitumor effects of berberine.

In conclusion, the present study provides insight into the mechanism underlying the inhibition of cell growth in human prostate cancer cells following treatment with berberine. These results may serve as the basis studies for further investigation into the effects of berberine as a prostate cancer treatment.

\section{References}

1. Semenas J, Allegrucci C, Boorjian SA, et al: Overcoming drug resistance and treating advanced prostate cancer. Curr Drug Targets 13: 1308-1323, 2012.

2. Kohli $M$ and Tindall DJ: New developments in the medical management of prostate cancer. Mayo Clin Proc 85: 77-86, 2010.
3. Martin SK, Vaughan TB, Atkinson T, et al: Emerging biomarkers of prostate cancer (Review). Oncol Rep 28: 409-417, 2012.

4. Hilton WM, Padalecki SS, Ankerst DP, et al: Temporal changes in the clinical approach to diagnosing prostate cancer. J Natl Cancer Inst Monogr 45: 162-168, 2012.

5. Paller CJ and Antonarakis ES: Management of biochemically recurrent prostate cancer after local therapy: evolving standards of care and new directions. Clin Adv Hematol Oncol 11: 14-23, 2013.

6. Khin-Maung U, Myo K, Nyunt-Nyunt W, et al: Clinical trial of berberine in acute watery diarrhoea. Br Med J (Clin Res Ed) 291: 1601-1605, 1985.

7. Han J, Lin H and Huang W: Modulating gut microbiota as an anti-diabetic mechanism of berberine. Med Sci Monit 17: RA164-167, 2011.

8. Yin J, Zhang $\mathrm{H}$ and Ye J: Traditional chinese medicine in treatment of metabolic syndrome. Endocr Metab Immune Disord Drug Targets 8: 99-111, 2008.

9. Liang KW, Ting CT, Yin SC, et al: Berberine suppresses MEK/ERK-dependent Egr-1 signaling pathway and inhibits vascular smooth muscle cell regrowth after in vitro mechanical injury. Biochem Pharmacol 71: 806-817, 2006.

10. Lin TH, Kuo HC, Chou FP, et al: Berberine enhances inhibition of glioma tumor cell migration and invasiveness mediated by arsenic trioxide. BMC Cancer 8: 58, 2008.

11. Liu B, Wang G, Yang J, et al: Berberine inhibits human hepatoma cell invasion without cytotoxicity in healthy hepatocytes. PLoS One 6: e21416, 2011.

12. Wang L, Liu L, Shi Y, et al: Berberine induces caspase-independent cell death in colon tumor cells through activation of apoptosis-inducing factor. PLoS One 7: e36418, 2012.

13. Piyanuch R, Sukhthankar M, Wandee G, et al: Berberine, a natural isoquinoline alkaloid, induces NAG-1 and ATF3 expression in human colorectal cancer cells. Cancer Lett 258: 230-240, 2007.

14. Park KS, Kim JB, Bae J, et al: Berberine inhibited the growth of thyroid cancer cell lines $8505 \mathrm{C}$ and TPC1. Yonsei Med J 53: 346-351, 2012.

15. Fu L, Chen W, Guo W, et al: Berberine targets AP-2/hTERT, $\mathrm{NF}-\kappa \mathrm{B} / \mathrm{COX}-2, \mathrm{HIF}-1 \alpha / \mathrm{VEGF}$ and cytochrome-C/caspase signaling to suppress human cancer cell growth. PLoS One 8: e69240, 2013.

16. Wang L, Cao H, Lu N, et al: Berberine inhibits proliferation and down-regulates epidermal growth factor receptor through activation of $\mathrm{Cbl}$ in colon tumor cells. PLoS One 8: e56666, 2013.

17. Sun KK, Ji C, Li X, et al: Overexpression of high mobility group protein $\mathrm{B} 1$ correlates with the proliferation and metastasis of lung adenocarcinoma cells. Mol Med Rep 7: 1678-1682, 2013.

18. Sun KK, Zhong N, Yang Y, et al: Enhanced radiosensitivity of NSCLC cells by transducer of erbB2.1 (TOB1) through modulation of the MAPK/ERK pathway. Oncol Rep 29: 2385-2391, 2013.

19. Che J, Lu YW, Sun KK, et al: Overexpression of TOB1 confers radioprotection to bronchial epithelial cells through the MAPK/ERK pathway. Oncol Rep 30: 637-642, 2013.

20. Li J, Cao B, Liu X, et al: Berberine suppresses androgen receptor signaling in prostate cancer. Mol Cancer Ther 10: 1346-1356, 2011.

21. Vidal A and Koff A: Cell-cycle inhibitors: three families united by a common cause. Gene 247: 1-15, 2000.

22. Mantena SK, Sharma SD and Katiyar SK: Berberine inhibits growth, induces G1 arrest and apoptosis in human epidermoid carcinoma A431 cells by regulating Cdki-Cdk-cyclin cascade, disruption of mitochondrial membrane potential and cleavage of caspase 3 and PARP. Carcinogenesis 27: 2018-2027, 2006.

23. Chidambara Murthy KN, Jayaprakasha GK and Patil BS: The natural alkaloid berberine targets multiple pathways to induce cell death in cultured human colon cancer cells. Eur J Pharmacol 688: 14-21, 2012.

24. Okada H and Mak TW: Pathways of apoptotic and non-apoptotic death in tumour cells. Nat Rev Cancer 4: 592-603, 2004.

25. Patil JB, Kim J and Jayaprakasha GK: Berberine induces apoptosis in breast cancer cells (MCF-7) through mitochondrial-dependent pathway. Eur J Pharmacol 645: 70-78, 2010.

26. Prenzel N, Fischer OM, Streit S, et al: The epidermal growth factor receptor family as a central element for cellular signal transduction and diversification. Endocr Relat Cancer 8: 11-31, 2001. 